\title{
Pearls
}

\section{Shelf Pricing for Distal Radius Fracture Implants}

\author{
Pedro K. Beredjiklian MD
}

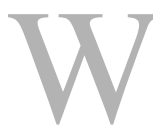

ith ongoing efforts to improve value in orthopaedic surgery, there is a growing focus on the costs associated with the delivery of medical care. For example, the recent introduction of bundled-care payment programs for total joint arthroplasty represents an effort by the Centers for Medicare \& Medicaid Services and other insurers to hold the physician financially accountable [1]. Of the total expenditures in orthopaedic surgery, implants are by far the largest contributor, with some studies estimating the implant to account for up to $87 \%$ of the total cost of the surgical procedure [4].

\section{A note from the Editor-in-Chief:}

We are pleased to present the next installment of "Pearls", a column in Clinical Orthopaedics and Related Research ${ }^{\mathbb{R}}$. In this column, distinguished surgeons, scientists, or scholars share surgical or professional tips they use to help surmount important or interesting problems. We welcome reader feedback on all of our columns and articles; please send your comments to

eic@clinorthop.org.

The author (PKB) has received stock ownership from Wright Medical (Memphis, TN, USA).

The author (PKB) also has received equity interest from Rothman Orthopaedic Surgery Hospital (Philadelphia, PA, USA),

Physicians' Care Surgical Hospital

(Royersford, PA, USA), Riddle Surgical
Shelf pricing, or price standardization, is well known and has been successfully established for arthroplasty implants [2]. While total joint replacement devices do represent a large fraction of societal costs as it relates to orthopaedic implants, applying the same approach to other areas may lead to considerable cost savings.

Dozens of commercially available fixed-angle plates and screws are used for the treatment of distal radius fractures. In spite of the variety available, no implant has emerged to demonstrate superior outcomes. The vast majority of fractures can be treated

Center (Media, PA, USA), and Riverview Surgical Center (Philadelphia, PA, USA) an amount more than USD 1,000,001. All ICMJE Conflict of Interest Forms for authors and Clinical Orthopaedics and Related Research ${ }^{\circledR}$ editors and board members are on file with the publication and can be viewed on request.

The opinions expressed are those of the writers, and do not reflect the opinion or policy of $\operatorname{CORR}^{\mathbb{R}}$ or The Association of Bone and Joint Surgeons ${ }^{\mathbb{R}}$.

P. K. Beredjiklian MD ( $₫)$

Division of Hand Surgery, The Rothman Institute, 925 Chestnut Street,

Philadelphia, PA 19107, USA

e-mail:

Pedro.Beredjiklian@rothmaninstitute.com; pedro_hand_doc@yahoo.com with any of these devices, in spite of minor design and appearance differences. The implant costs across manufacturers can vary greatly, often without any justification.

Our practice includes 11 orthopaedic fellowship-trained hand surgeons. Upon review of the distal radius fracture implant costs in our hospitals and ambulatory surgical centers, we found that they varied widely, with the higher cost implants costing almost three times more than the less-expensive ones. For the most costly implants, the total implant cost per case accounted almost $100 \%$ of the Medicare reimbursement to the facility. As has been reported by others [3], the surgeons using these devices in our practice had little knowledge of the cost differences among the implants they used, and generally chose their implants based on familiarity without cost consideration.

In order to minimize cost and standardize pricing, and after agreement by all physicians, a contractual agreement was drawn between the facilities and implant vendors that wanted to have their devices used in our facilities. In the contract, a fixed, low-but-fair shelf price for a "standard" plate and an unlimited number of screws per surgical case was established. Based on the last estimates and after 2 years of 


\section{Pearls}

the contract, the centers have realized a savings of almost USD 250,000 as a result of this cost-control measure. Based on our experience, the following steps can be taken to achieve successful implantation of this type of program:

(1) Identify devices that are amenable to shelf pricing.

Commonly used implants that are available in similar forms from multiple vendors are the best targets, as manufacturers have a greater incentive to lower profit to gain market share. Plates and screws for fracture fixation and suture anchors are examples. Niche, highly specialized implants are not good candidates for these efforts.

(2) Inform the surgeons of the cost differences among implants.

Decisions about the implementation of the program must be agreed upon by consensus-all of the physicians must buy into the process. Since most of these devices are very similar, most surgeons are facile with multiple systems, and there is little added expense in surgical time and training if an alternative implant needs to be used. Patient care should never be compromised.

(3) Reach a fair price point for these implants.
The lowest-priced implant is a reasonable target. Some insurance carriers reimburse surgical facilities for the implant in addition to the facility fee, typically above a cost threshold. The price point should not be lower than this threshold. Also, the facilities do not want to be priced out completely as the devices are needed for patient care. In our case, only one of more than a dozen vendors did not agree to the fixed price at the deadline, and all of surgeons maintained the use of their implant of choice without any change in their practices.

(4) Agree on a price point that includes all of the materials needed to complete the procedure.

Negotiating the price for just a plate will not lead to cost savings if the screws double in price after the contract is in place.

(5) Establish a hard deadline for the agreement for all vendors.

Include a "blackout" period in which the vendors who did not sign on by the cutoff date would have to wait before signing the agreement if they chose to participate at a later time. This will incent the vendors to sign the agreement instead of waiting after the deadline to determine what their competitors did. Our blackout period was 3 months.
(6) Let the hospital or ambulatory surgical center administrators negotiate the contracts.

Physicians are seldom good negotiators, and often (as in our case) implant company representatives made direct individual appeals to each surgeon they knew personally in an effort to stop the process prior to the deadline.

\section{References}

1. Bernstein J. Not the Last Word: Learned Helplessness and Medicare's Bungled Bundled Payment Program. Clin Orthop Relat Res. 2016;474: 1919-1923.

2. Bosco JA, Alvarado CM, Slover JD, Iorio R, Hutzler LH. Decreasing total joint implant costs and physician specific cost variation through negotiation. J Arthroplasty. 2014;29:678680.

3. Okike K, O'Toole RV, Pollak AN, Bishop JA, McAndrew CM, Mehta S, Cross WW 3rd, Garrigues GE, Harris MB, Lebrun CT. Survey finds few orthopedic surgeons know the costs of the devices they implant. Health Aff (Millwood). 2014;33:103-109.

4. Robinson JC, Pozen A, Tseng S, Bozic KJ. Variability in costs associated with total hip and knee replacement implants. J Bone Joint Surg Am. 2012;94:1693-1698. 